\title{
A Study on Intraocular Pressure Elevation after Intravitreal 4mg Triamcinolone Acetonide Injection in Treatment of Macular Edema among North India Population
}

\author{
Shipra Tripathi ${ }^{1}$, Amit Sood ${ }^{2}$ \\ ${ }^{1}$ Assistant Professor, Department of Ophthalmology, Varun Arjun Medical College Banthara, ${ }^{2}$ Assistant Professor, Department of Ophthalmology, autonomous state \\ Medical College, Shahjahnpur.
}

\section{Abstract}

Background: Macular edema is one of the leading causes for impaired vision in some retinal vascular disorders. Recent clinical studies suggest that intravitreal injection of triamcinolone acetonide (IVTA) may be a therapeutic option for the treatment of macular edema. In 1995, Penfold et al reported a pilot study of intravitreal injection of 4mg of triamcinolone acetonide (IVTA) to treat exudative age-related macular degeneration with encouraging results. Subjects and Methods: A prospective, non-comparative study was performed with 100 patients (100 eyes) who received $4 \mathrm{mg} / 0.1 \mathrm{~mL}(40 \mathrm{~g} / \mathrm{L})$ IVTA injection for macular edema and who were followed-up for a minimum of 3 months at the Department of Ophthalmology. Patients using steroid eye drops or systemic steroid, those previously treated with subconjunctival or subtenon steroid injection, and those with a history of glaucoma were excluded from the study. Results: Of the 100 eyes, 50 were from women and 50 were from men; the mean age was $56.3 \pm 11.4$ years. Reason for the IVTA was progressive declining of visual acuity due to macular edema associated with retinal vein occlusion (60 eyes), or diabetic retinopathy (40 eyes). IOP increased significantly ( $\mathrm{p}<0.001$ ) from $14.95 \pm 2.83 \mathrm{mmHg}$ preoperatively to a mean maximum of $19.01 \pm 5.92 \mathrm{mmHg}$ postoperatively. Conclusion: According to our results, intravitreal injection of $4 \mathrm{mg}$ of triamcinolone acetonide can lead to significant IOP elevation in approximately one-third of patients, occurring at a mean of 4 weeks after injection. The findings of our study suggest that the IVTA in a dosage of $4 \mathrm{mg}$ could lead to a secondary ocular hypertension.

Keywords: Intraocular Pressure, Intravitreal Injection, Macular Edema.

Corresponding Author: Dr. Amit Sood, Assistant Professor, department of Ophthalmology, autonomous state Medical College, Shahjahnpur.

Received: September 2019

Accepted: September 2019

\section{Introduction}

Macular edema is one of the leading causes for impaired vision in some retinal vascular disorders. Recent clinical studies suggest that intravitreal injection of triamcinolone acetonide (IVTA) may be a therapeutic option for the treatment of macular edema. In 1995, Penfold et al reported a pilot study of intravitreal injection of $4 \mathrm{mg}$ of triamcinolone acetonide (IVTA) to treat exudative agerelated macular degeneration with encouraging results. ${ }^{[1]}$ Thereafter, intravitreal injection of triamcinolone acetonide became a useful therapeutic option for many conditions, including ocular inflammatory diseases, ${ }^{[2]}$ retinal venoocclusive disease, ${ }^{[3]}$ diabetic macular edema and ocular choroidal neovascularization. ${ }^{[4,5]}$ One of the ocular side effects of corticosteroids is the elevation of intraocular pressure (IOP)..$^{[6,7]}$

Intravitreal steroid injection has been widely used in the field of ophthalmology since intravitreal dexamethasone injection was first performed for the treatment of endophthalmitis by Graham and associates in 1974. ${ }^{[8]}$ Among steroids, triamcinolone acetonide is hydrophobic so that its vitreous level can be maintained for up to 3 months. ${ }^{[9,10]}$ In addition, its fibroblast growth inhibition effect is 21 -fold more forceful than that of dexamethasone. Intravitrea ltriamcinolone acetonide (IVTA) injection has been widely used to treat several intra ocular neovascular, inflammatory, and edematous diseases. ${ }^{[1-16]}$ However, steroid induced increase in the intraocular pressure (IOP) is one of the most-widely cited side effects of IVTA injection. ${ }^{[17,18]}$ A significant amount of cortico steroid passes to intravitreal issues after the injection, leading to a significant elevation in the IOP.

As the expansion of indications and use of IVTA increases, the incidence of corticosteroid-induced glaucoma associated with IVTA will become more commonly encountered by ophthalmologists. The main purpose of this study is to conduct a global Meta-analysis for a post IVTA-injection elevation of IOP and to find the main factors behind such an elevation. Such an analysis will shed light on the evolution of IOP after an IVTA injection and allow comparing possible advantages and disadvantages of the procedure. To the best of our knowledge, this is the most comprehensive and the only global Meta-analytic research for a post IVTAinjection elevation of IOP after an IVTA injection. 
Moreover, our paper is also unique in presenting the Metaanalytic results along with a Meta-regression analysis in this area of research.

\section{Subjects and Methods}

A prospective, non-comparative study was performed with 100 patients (100 eyes) who received $4 \mathrm{mg} / 0.1 \mathrm{~mL}(40 \mathrm{~g} / \mathrm{L})$ IVTA injection for macular edema and who were followedup for a minimum of 3 months at the Department of Ophthalmology. Patients using steroid eye drops or systemic steroid, those previously treated with subconjunctival or subtenon steroid injection, and those with a history of glaucoma were excluded from the study.

The procedure was administered with topical anesthesia. After sterilization of the periocular area with $5 \%$ povidone iodine, $4 \mathrm{mg}$ triamcinolone acetonide was injected with a 26 $\mathrm{G}$ needle at the inferonasal or inferotemporal site, $3.5 \mathrm{~mm}$ from the limbus. Paracentesis was not performed. Patients were maintained in upright position for 24 hours after IVTA injection and antibiotic topical medication (levofloxacin) was administered 4 times per day for 1-2 weeks.

Each patient's IOP was evaluated before the injection, ${ }^{[8,10]}$ and 14 days after the injection, and monthly afterwards using a noncontact tonometer (TOPCON CT-80). Mean IOP of three measurement was used, and when the measured pressure by the noncontact tonometer was over 21 $\mathrm{mmHg}$, IOP was remeasured with Goldman applanation tonometer to reduce errors. A significant IOP elevation was defined as IOP $>21 \mathrm{mmHg}$ or a rise of more than $5 \mathrm{mmHg}$ in patients with IOP over $21 \mathrm{mmHg}$ on their first examination. Correlations with age, sex, underlying diabetes mellitus or hypertension, refractive error, and previous ophthalmologic operation history were also analyzed to investigate the factors related to IOP elevation.

\section{Results}

Of the 100 eyes, 50 were from women and 50 were from men; the mean age was $56.3 \pm 11.4$ years. Reason for the IVTA was progressive declining of visual acuity due to macular edema associated with retinal vein occlusion (60 eyes), or diabetic retinopathy (40 eyes).

Table 1: Intraocular pressure (mean \pm SD) before and after the intravitreal injection of $4 \mathrm{mg}$ triamcinolone acetonide; $P$ value: difference between the postoperative value and the preoperative value

\begin{tabular}{|l|l|l|l|}
\hline & $\begin{array}{l}\text { Number of } \\
\text { eyes }\end{array}$ & $\begin{array}{l}\text { IOP } \\
(\mathbf{m m H g})\end{array}$ & $\mathbf{P}$ \\
\hline Pre-op & 100 & $14.95 \pm 2.83$ & $<0.001$ \\
\hline 14d post-op & 100 & $15.98 \pm 2.57$ & $<0.001$ \\
\hline 1mo post-op & 100 & $18.04 \pm 5.61$ & $<0.001$ \\
\hline 2mo post-op & 100 & $19.01 \pm 5.92$ & $<0.001$ \\
\hline 3mo post-op & 100 & $17.12 \pm 4.31$ & $<0.001$ \\
\hline 4mo post-op & 100 & $16.73 \pm 2.84$ & $<0.001$ \\
\hline 5mo post-op & 100 & $15.81 \pm 2.37$ & $<0.001$ \\
\hline 6mo post-op & 100 & $15.76 \pm 2.10$ & $<0.001$ \\
\hline
\end{tabular}

IOP increased significantly $(\mathrm{p}<0.001)$ from $14.95 \pm 2.83$ $\mathrm{mmHg}$ preoperatively to a mean maximum of $19.01 \pm 5.92$ $\mathrm{mmHg}$ postoperatively.

Table 2: The number of eyes with IOP elevation above baseline in each interval after the intravitreal injection of $4 \mathrm{mg}$ triamcinolone acetonide

\begin{tabular}{|c|c|c|c|c|c|c|c|}
\hline & 14d & $1 \mathrm{mo}$ & $2 \mathrm{mo}$ & $3 \mathrm{mo}$ & $4 \mathrm{mo}$ & $5 \mathrm{mo}$ & $6 \mathrm{mo}$ \\
\hline $\mathrm{IOP} \geq 21 \mathrm{mmHg}$ & 3 & 16 & 20 & 10 & 6 & 0 & 0 \\
\hline IOP rise $\geq 5 \mathrm{~mm} \mathrm{Hg}$ & 2 & 18 & 25 & 12 & 4 & 0 & 0 \\
\hline $\mathrm{IOP}$ rise $\geq 10 \mathrm{~mm} \mathrm{Hg}$ & 1 & 6 & 16 & 3 & 0 & 0 & 0 \\
\hline
\end{tabular}

A rise in IOP to values higher than $21 \mathrm{mmHg}$ was observed in $3(3 \%)$ eyes 14 days after injection. The peak was reached in 2 months after injection, which was $20 \mathrm{mmHg}(20 \%)$. Within 2 months after IVTA, 25 eyes (25\%) demonstrated an increase in IOP of $5 \mathrm{mmHg}$ or greater, and 16 eyes $(16 \%)$ had an increase in IOP of $10 \mathrm{mmHg}$ or greater.

\section{Discussion}

Macular edema is the major cause of decreased visual acuity in diabetic retinopathy and retinal veinocclusion. A damaged blood-retinal barrier due to capillary leakage can cause macular edema. Corticosteroids have long been known to tighten up blood vessels resulting in a decrease of vessel leakage. Triamcinolone acetonide was demonstrated to reduce the breakdown of blood-retinal barrier after intravitreal application and was used to treat macular edema secondary to retinal vein occlusion and diabetic retinopathy by means of anti-inflammatory and blood-retinal barrier stabilizing effects. ${ }^{[19-24]}$ Corticosteroids are well known for their effectiveness in the inhibition of prostaglandin, ${ }^{[25]}$ inflammatory adhesion molecules such as ICAM-I and MHC-II, growth factors such as vascular endothelial growth factor (VEGF) and in the induction of plasminogen activator inhibitor (PAI)-1. As a result, they tighten up the blood vessels and maintain the integrity of the blood-retinal barrier. Consequently, steroids have been used for the treatment of various ocular diseases, when applied either topically or systemically. However, the eyes account for only $0.01 \%$ of the entire body volume, so in order to treat an ocular disease, systemic medication in the place of intraocular direct injection will need a significantly higher dosage to reach the same intraocular concentration, with the consequence of more systemic side effects.

Jonas, ${ }^{[17]}$ have also reported the IOP responded to intravitreal injection of $8 \mathrm{mg}$ triamcinolone acetonide. In this retrospective review of 75 eyes of 71 patients, $52 \%$ of eyes experienced a pressure elevation higher than $21 \mathrm{mmHg}$ with the rise occurring at a mean of 2 months. In our study, the elevation of intra ocular pressure was seen at 14 days and peaked at 2 months after IVTA. 
It is not known whether the responses that were seen in these diabetic subjects were genetically determined or merely modified by ocular complications or other vascular, metabolic, or endocrine changes in the diabetes. ${ }^{[26]}$

As described above, IOP elevation after IVTA injection is a common and now well-documented side-effect, but with large variation in incident rate. Considering some of the patients whose IOP was not controlled and who had to undergo filtering surgery or vitrectomy, determining the risk factors of IOP elevation and the patterns of increased IOP after IVTA injection will provide considerable help in prescribing the treatment, recommending the injection and observing the follow up. Accordingly, in this study, we investigated the known risk factors of IOP elevation from the usage of systemic or topical steroids. Regarding the difference in the mean elimination half-life of triamcinolone in the vitrectomized eye and the nonvitrectomized patients, we investigated the relations of IOP elevation on the basis of previous ophthalmologic operation history.

From a clinical point of view it may be important that in all eyes, the IOP could be controlled by topical antiglaucomatous treatment, meaning that it is feasible to inject triamcinolone acetonide to vitreous.

\section{Conclusion}

According to our results, intravitreal injection of $4 \mathrm{mg}$ of triamcinolone acetonide can lead to significant IOP elevation in approximately one-third of patients, occurring at a mean of 4 weeks after injection. The findings of our study suggest that the IVTA in a dosage of $4 \mathrm{mg}$ could lead to a secondary ocular hypertension; that the rise of IOP may persist at least 6 months after the injection; that the rise of IOP can usually be controlled by topical antiglaucomatous medication; and that the steroid induced ocular hypertension may thus not be a major contraindication against the use of intravitreal triamcinolone acetonide as treatment trial of macular edema owing to diabetic retinopathy and retinal vein occlusion.

\section{References}

1. Penfold PL, Gyovy JF, Hunyor AB, et al. Exudative macular degeneration and intravitreal triamcinolone - a pilot study. Aust NZ J Ophthalmol1995;23:293-8.

2. Young S, Larkin G, Branley $\mathrm{M}$, et al. Safety and efficacy of intravitreal triamcinolone for cystoid macular edema in uveitis. Clin Exp Ophthalmol2001;29:2-6.

3. Greenberg PB, Martidis A, Roger AH, et al. Intravitreal triamcinolone acetonide for macular edema due to central retinal vein occlusion. Br J Ophthalmol 2002; 86:247-8.

4. Jonas JB, Sofker A. Intraocular injection of crystalline cortisone as adjunctive treatment of diabetic macular edema. Am J Ophthalmol2001;132:425-7.

5. Danis RP, Ciulla TA, Pratt LM, et al. Intravitreal triamcinolone acetonide in exudative age-related macular degeneration Retina2000;20:244-50.

6. McLean JM. Use of ACTH and cortisone. Trans Am Ophthalmol Soc1950;48:293-6.

7. Francois J. Cortisone et tension oculaire. Ann D'Oculist 1984;187:805.

8. Graham RO, Peyman GA. Intravitreal injection of dexamethasone. Treatment of experimentally induced endophthalmitis. Arch Ophthalmol 1974;92:149-54.

9. Beer PM, Bakri SJ, Singh RJ, et al. Intraocular concentration and pharmacokinetics of triamcinolone acetonide after a single injection. Ophthalmology 2003;110:681-6.

10. Jonas JB. Intraocular availability of triamcinolone acetonide after intravitreal injection. Am J Ophthalmol 2004;137: 560-2.

11. Martidis A, Duker JS, Greenberg PB, Rogers AH, Puliafito CA, Reichel E, Baumal, C. Intravitreal triamcinolone for refractory diabetic macular edema. 2002;109(5):920-927.

12. Ip MS, Kumar KS. Intravitreous triamcinolone acetonide as treatment for macular edema from central retinal vein occlusion. 2002; 120(9):1217-1219.

13. Antcliff RJ, Spalton DJ, Stanford MR, Graham EM, ffytche TJ, Marshal 1J. Intravitreal triamcinolone for uveitic cystoids macular edema: an optical coherence tomography study. 2001; 108(4): 765772.

14. Benhamou N, Massin P, Haouchine B, Audren F, Tadayoni R, Gaudric A. Intravitreal triamcinolone for refractory pseudophakic macular edema. 2003;135(2):246-249.

15. Tano Y, Chandler D, Machemer R. Treatment of intraocular proliferation with intravitreal injection of triamcinolone acetonide. 1980;90(6):810-816.

16. Danis RP, Bingaman DP, Yang Y, Ladd B. Inhibition of preretinal and optic nerve head neovascularisation in pigs by intravitreal triamcinolone acetonide. 1996;103(12):2099-2104.

17. Jonas JB, Degenring RF, Kreissig I, Akkoyun I, Kamppeter BA. Intraocular pressure elevation after intravitreal triamcinolone acetonide injection. 2005;112(4):593-598.

18. Smithen LM, Ober MD, Maranan L, Spaide RF. Intravitreal triamcinolone acetonide and intraocular pressure. 2004;138(5): 740743.

19. Wilson CA, Berkowtiz BA, Sato Y, Ando N, Handa JT, deJuan EJR.Treatment within travitreal steroid reduces blood-retinal barrier breakdown due to retinal photo coagulation. 1992;10:1155-1159

20. Zhang YB, Cheng XL, Dong J. Treatment of diabetic macular edema by dual intravitreal injections of triamcinolone. 2005;5(6):1207-1210

21. Zkiris A, Evereklioglu C, Erkilic K, Tamcelik N, Mirza E. Intravitreal triamcinolone acetonide injection as primary treatment for diabetic macular edema. 2004;14:543-549

22. Ciulla TA, Walker JD, Fong DS, Criswell MH. Corticosteroids in posterior segment disease: An update on new delivery systems and new indications. 2004;15:211-220

23. Becker B, Bresnick G, Chevrette L, Kolker AE, Oaks MC, Cibis A. Intraocular pressure and its response to topical corticosteroids in diabetes. 1966;76:477-483

24. Irooka K, Shiraga F, Tanaka S, Baba T, Mandai H. Risk factors for elevated intraocular pressure after trans-tenonretrobulbar injections of triamcinolone. 2006;50(3):235-238

25. Floman N, Zor U. Mechanism of steroid action in ocular inflammation: inhibition of prostaglandin production. Invest Ophthalmol Vis Sci 1997;16:69-73.

26. Irooka K, Shiraga F, Tanaka S, Baba T, Mandai H. Risk factors for elevated intraocular pressure after trans-tenonretrobulbar injections of triamcinolone. 2006;50(3):235-238. 
Copyright: ( ) the author(s), 2019. It is an open-access article distributed under the terms of the Creative Commons Attribution License (CC BY 4.0), which permits authors to retain ownership of the copyright for their content, and allow anyone to download, reuse, reprint, modify, distribute and/or copy the content as long as the original authors and source are cited.

How to cite this article: Tripathi S, Sood A. A Study on Intraocular Pressure Elevation after Intravitreal 4mg Triamcinolone Acetonide Injection in Treatment of Macular Edema among North India Population. Asian J. Med. Res. 2019;8(3):OT05-OT08.

DOI: dx.doi.org/10.21276/ajmr.2019.8.3.OT2

Source of Support: Nil, Conflict of Interest: None declared. 